Proceeding Paper

\title{
Comparison of Remote Sensing Soil Electrical Conductivity from PlanetScope and Ground Measured Data in Wheat and Beet Yields ${ }^{\dagger}$
}

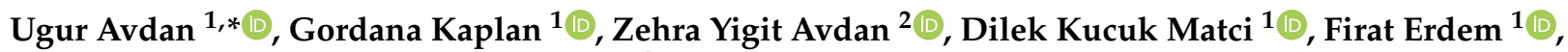 \\ Ece Tugba Mizik ${ }^{2}$ and Ilknur Demirtas ${ }^{2} \mathbb{D}$
}

check for updates

Citation: Avdan, U.; Kaplan, G.; Avdan, Z.Y.; Matci, D.K.; Erdem, F.; Mizik, E.T.; Demirtas, I. Comparison of Remote Sensing Soil Electrical Conductivity from PlanetScope and Ground Measured Data in Wheat and Beet Yields. Biol. Life Sci. Forum 2021 3, 48. https://doi.org/10.3390/ IECAG2021-09741

Academic Editor: Youssef Rouphael Published: 1 May 2021

Publisher's Note: MDPI stays neutral with regard to jurisdictional claims in published maps and institutional affiliations.

Copyright: (C) 2021 by the authors. Licensee MDPI, Basel, Switzerland. This article is an open access article distributed under the terms and conditions of the Creative Commons Attribution (CC BY) license (https:// creativecommons.org/licenses/by/ $4.0 /)$.
1 Institute of Earth and Space Sciences, Eskisehir Technical University, 26555 Eskisehir, Turkey; kaplangorde@gmail.com (G.K.); dkmatci@anadolu.edu.tr (D.K.M.); firaterdem5@gmail.com (F.E.)

2 Department of Environmental Engineering, Faculty of Engineering, Eskisehir Technical University, 26555 Eskisehir, Turkey; zyigit@eskisehir.edu.tr (Z.Y.A.); ecemizik@gmail.com (E.T.M.); ilknurozudogru@eskisehir.edu.tr (I.D.)

* Correspondence: uavdan@eskisehir.edu.tr

† Presented at the 1st International Electronic Conference on Agronomy, 3-17 May 2021; Available online: https:/ / iecag2021.sciforum.net/.

\begin{abstract}
Soil salinity is a major threat to the continuity of sustainable agriculture and food provision and the soil structure deterioration. In this context, determining, reducing and managing soil salinity is very important for creating sustainable modern agriculture. Determining soil salinity is generally carried out in the laboratory environment and devices used in land plots. Remote sensing is one of the important methods used for precise estimation and mapping of salinity. With remote sensing technology, soil salinity maps for large areas can be obtained with low cost and low effort. This study aims to compare remote sensing soil electrical conductivity from PlanetScope and ground measured data in wheat and beet fields in the farming areas of Alpu, Turkey. For that reason, electrical conductivity was measured at several points in wheat and beet fields using in-situ measurements and compared with various soil salinity indices from PlanetScope imagery acquired on the same day. Linear regression analysis was carried out to correlate the electrical conductivity data with their corresponding soil salinity spectral index values. The results show a high correlation $\left(\mathrm{R}^{2}=0.84\right)$ between soil salinity in wheat fields and some of the used indices. This study strengthens the idea that soil salinity maps can be obtained fast and accurately for large areas using remote sensing technology.
\end{abstract}

Keywords: remote sensing; soil salinity; electrical conductivity; PlanetScope; salinity index

\section{Introduction}

The soil is a building block that forms the basis of life. The evolution of humanity from the understanding of the hunter community to the agricultural society has led to the strengthening of humanity's connection with the soil and the study of the soil. The modern agricultural process, which has emerged today with developing technology and increasing population, focuses on increasing crop yields rather than soil. However, environmental issues, such as climate change, food and water security, land degradation, and the impact of habitat loss on species, have shown that soil characteristics other than crop yields also need to be studied [1]. Therefore, soil characteristics evaluation is crucial in terms of soil sustainability on a local and regional scale [2].

It is estimated that $20 \%$ of the world's total cultivated areas and $33 \%$ of irrigated agricultural land are negatively affected by high salinity [3,4]. Besides, an estimated 1 million hectares of agricultural land in the European Union, including Mediterranean countries, are affected by soil salinity, one of the biggest causes of desertification [5]. In semiarid and arid areas, low rainfall, high evaporation, high water table and a high amount 
of water-soluble salt cause soil salinity formation [6]. For this reason, restoration and land reclamation of soils facing the salinity problem is significant in terms of increasing Eco-Environmental Quality and ensuring regional sustainable development [7]. The EC value, which provides information about the salinity values in agricultural areas where wheat and beet are cultivated, varies due to irrigation. Long-term irrigation applications applied to crops and filtration of water from the soil can cause changes in the degree of soil salinity, $\mathrm{pH}$, ion exchange, and therefore the type of salinity in the soil. The high level of salinity is usually due to insufficient irrigation and drainage, as well as high evaporation of water from the soil [8]. The unit of EC, which refers to the salinity of the soil, is $\mathrm{mS} / \mathrm{cm}$. In this context, determining the spatial and temporal distribution of soil salinity and dynamic monitoring in ensuring soil sustainability can provide a quantitative assessment [9].

Since traditional laboratory analyses generally carry out soil characterization, the process is both costly and time-consuming. The difficulty of dynamically monitoring the temporal and spatial change of the salinization process of soils with large areas and determining the regions inclined to salinization [10] recently has been aided with remote sensing data and methods. In some studies, salinity indices were created using Landsat and Sentinel-2 satellite images, and salinity mapping was performed using several indices [11,12]. However, high spatial resolution maps could not be created because Landsat satellite images' spatial resolution is $30 \mathrm{~m}$. PlanetScope consists of more than 120 nanosatellites manufactured by Planet Labs, Inc., San Francisco, CA, USA. The PlanetScope system provides daily, high resolution ( $3 \mathrm{~m}$ ) and 4-band (red, green, blue, and near-infrared) satellite images [13].

Considering that not many studies can be found in the literature for soil salinity mapping using high-resolution imagery such as PlanetScope, this study aims to compare remote sensing soil electrical conductivity from PlanetScope and ground measured data in wheat and beet fields in the farming areas of Alpu, Turkey.

\section{Materials and Methods}

The study was carried out in the Alpu district of Eskişehir, Turkey. Alpu has an area of 1.059 .130 decares and an altitude of $700 \mathrm{~m} .400 .490$ decares of the region are used as agricultural land, 389.640 decares as forest land, 220.700 decares as meadow-pasture and 48.300 decares non-agricultural land. In agricultural production, 150.320 decares are used as irrigated agricultural land and 250,170 decares as barren agricultural land [14]. In this study, soil sampling was carried out using a random sampling method from the fields where the beet and wheat were cultivated in the Alpu region on 6 October 2020 and 7 October 2020. The coordinates of each measurement point were recorded using handheld GPS. The study area, together with in-situ measurements and the used PlanetScope image, is given in Figure 1.

The electrical conductivity (EC) at the measurement points was measured with PNT 3000 COMBI + device. Three measurements were made by electrical conductivity probe directly on the soil surface.

PlanetScope image of 07.10.2020 was used in the study. PlanetScope consists of more than 120 nano-satellites manufactured by Planet Labs, Inc. The PlanetScope system provides daily, very high resolution $(3 \mathrm{~m})$ and 4-band (red, green, blue, and near-infrared) satellite images [13]. Various spectral indices have been developed for detecting and mapping salinity. The spectral indices used in this study are given in Table 1. Linear regression analysis was carried out to correlate the electrical conductivity data with their corresponding soil salinity spectral index values. 


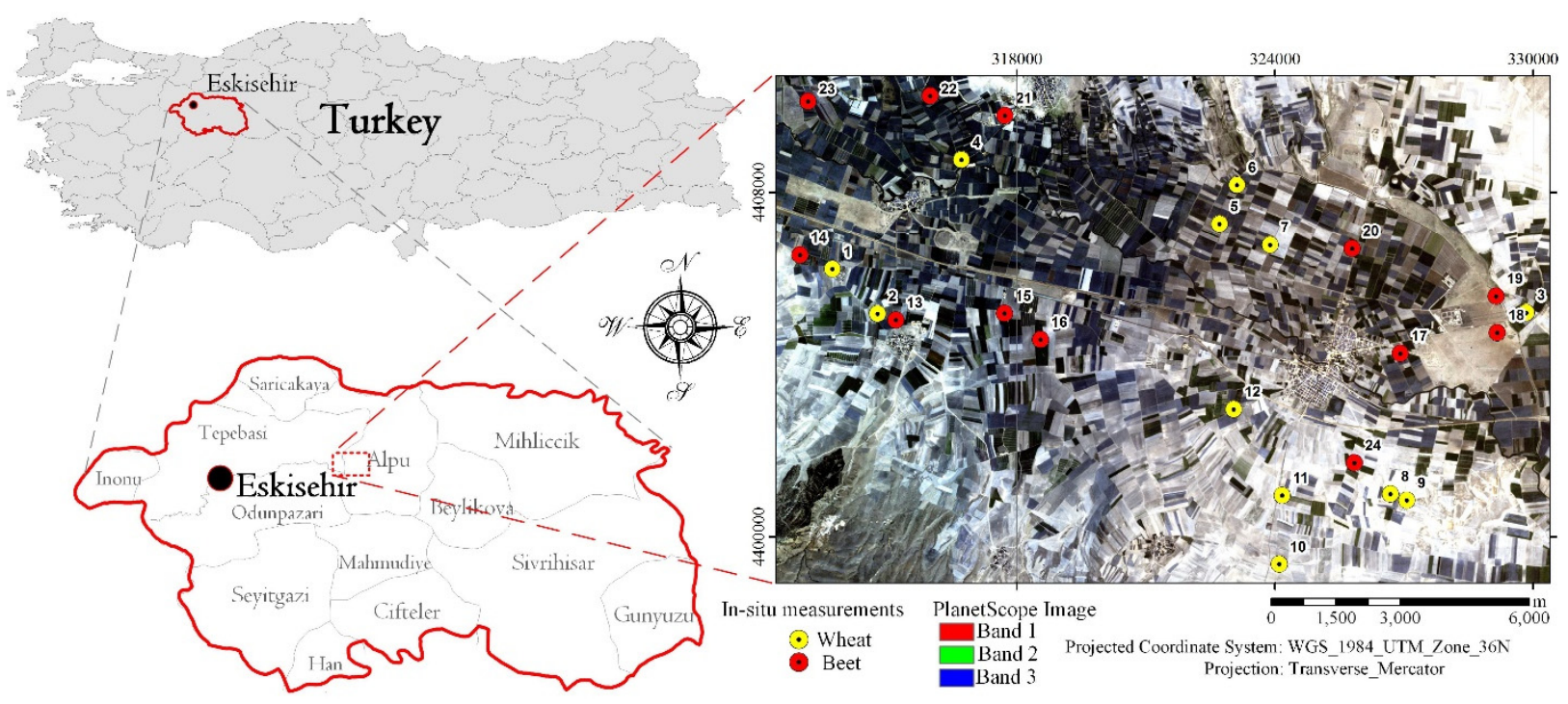

Figure 1. Study Area, in-situ measurements, and PlanetScope imagery.

Table 1. Spectral indices used in this study.

\begin{tabular}{ccc}
\hline Spectral Indices & Formula & Reference \\
\hline SI-1 & $\mathrm{SI}=\frac{B}{R}$ & {$[15]$} \\
SI-2 & $\mathrm{SI}=\frac{B}{B}$ R & {$[15]$} \\
SI-3 & $\mathrm{SI}=\frac{G \times R}{B}$ & {$[15]$} \\
SI-4 & $\mathrm{SI}=\frac{B \times R}{G}$ & {$[16]$} \\
\hline
\end{tabular}

Where $\mathrm{B}$ represents the blue band, $\mathrm{G}$ represents the green band, and $\mathrm{R}$ represents the red band of a satellite image Therefore, in this study, 1st (blue), 2nd (green), and 3rd (red) bands of PlanetScope image were used to calculate salinity indices.

\section{Results and Discussion}

The four investigated salinity indices (Table 1) and the wheat fields' in-situ measurements showed a significant correlation. In contrast, the beet fields' measurements did not show a significant correlation with the field measurements. While the correlations of the wheat fields ranges $\mathrm{R}^{2}=0.66-0.84(p<0.05)$, the correlations for the beet fields were $\mathrm{R}^{2}>0.1$ (Figure 2). Taking into consideration the high correlation between the salinity in the wheat fields with the investigated indices. Furthermore, we have investigated the potential for a linear regression model between the given variables. The results showed that, with the exclusion of SI-4, there is a significant relationship described with Equation (1).

$$
\hat{Y}=8.76 S I 1-79.64 S I 2-0.001 S I 3
$$

where $\hat{Y}$ is the predicted salinity, and SI are the investigated spectral indices (Table 1). The model showed significant regression statistics $\left(\mathrm{R}^{2}=0.95\right.$; Adjuster $\left.\mathrm{R}^{2}=0.83 ; p<0.05\right)$ in the study area with prediction power of $95 \%$ for the wheat fields. However, further investigation is needed for the accuracy assessment as the number of in-situ measurements is limited. 

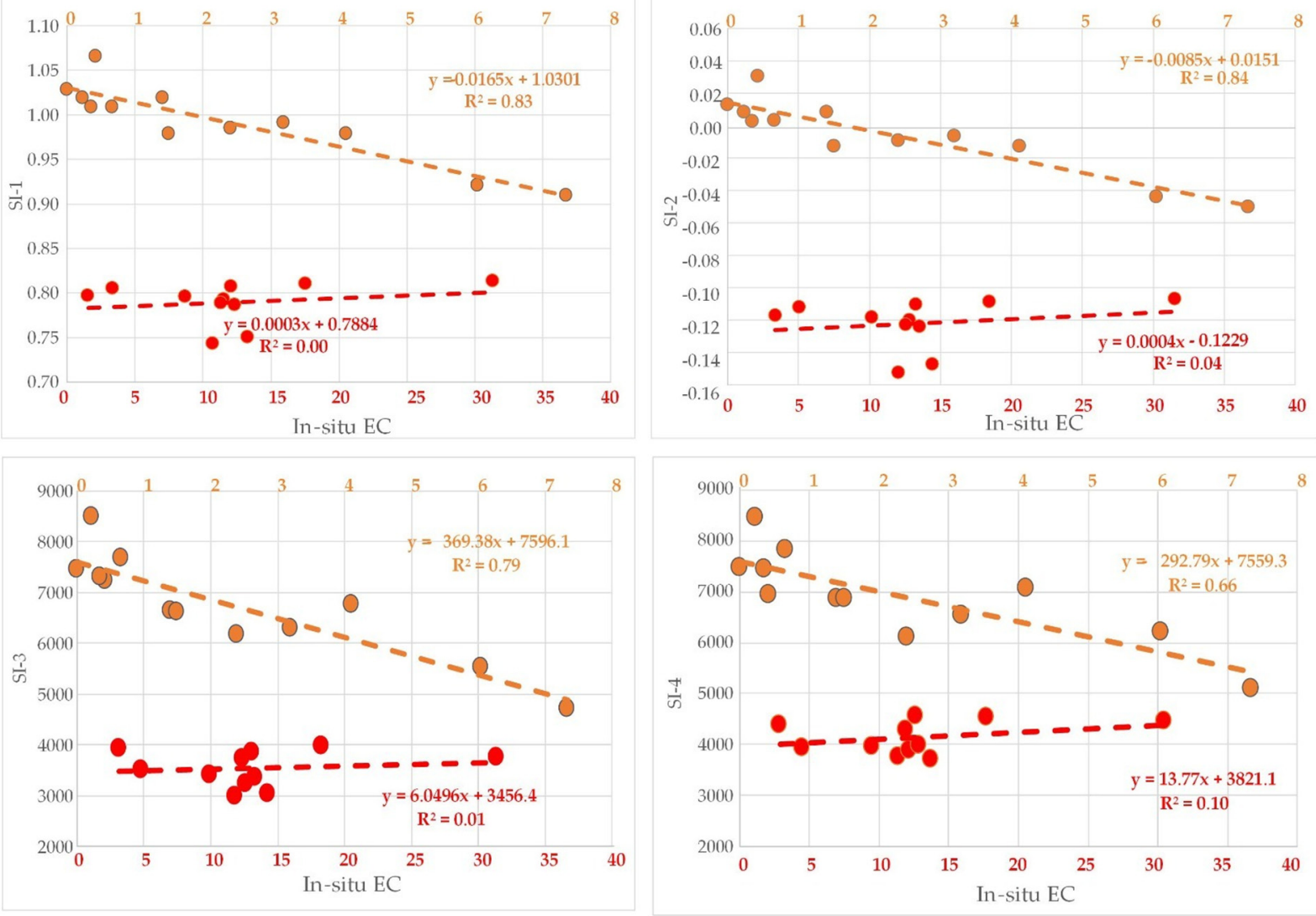

Figure 2. Correlation between in-situ measurements and the investigated SI (orange—wheat; redbeet).

\section{Conclusions}

The conducted study aimed at investigating the correlation between in-situ salinity measurements and spectral indices retrieved from PlanetScope satellite imagery in Alpu, Eskisehir, Turkey. After a significant correlation was established between wheat field measurements and satellite data, a regression model was developed with a prediction power of $95 \%$. No significant correlation was found in the beet field measurements. The results are significant as they point out that not all agricultural fields can be predicted with the same model. For future studies, we suggest investigating the relationship of soil indices such as SAVI and other salinity indices with soil salinity. In addition, we recommend that tests be carried out by increasing the area measurement points.

Supplementary Materials: The poster presentation can be downloaded at: https:/ /www.mdpi.com/ article/10.3390/IECAG2021-09741/s1.

Author Contributions: Conceptualization, U.A. and Z.Y.A.; methodology, U.A., G.K., Z.Y.A., D.K.M., F.E., E.T.M. and I.D.; software, G.K.; validation, G.K. and D.K.M.; formal analysis, F.E., E.T.M. and I.D.; investigation, G.K., D.K.M., F.E., E.T.M. and I.D.; resources, U.A. and Z.Y.A.; data curation, G.K. and D.K.M.; writing — original draft preparation, G.K., D.K.M., F.E., E.T.M. and I.D.; writing—review and editing, G.K., D.K.M., F.E., E.T.M. and I.D.; visualization, G.K. and D.K.M.; supervision, U.A. and Z.Y.A.; project administration, U.A. and Z.Y.A.; funding acquisition, U.A. All authors have read and agreed to the published version of the manuscript.

Funding: This study was supported by Eskisehir Technical University Scientific Research Projects Commission under grant no: 19ADP084.

Institutional Review Board Statement: Not applicable.

Informed Consent Statement: Not applicable. 
Data Availability Statement: PlanetScope satellite images can be accessed through the Planet company's data portal (https:/ / www.planet.com/products/planet-imagery/, accessed on 9 January 2021). The data that support the findings of this study are available from the corresponding author, [U.A.], upon reasonable request.

Acknowledgments: This work was supported by the Eskisehir Technical University Scientific Research Projects Commission (Project Number: 20ADP084). The authors want to thank Planet Labs, Inc. for providing the high-resolution Planet Scope imagery.

Conflicts of Interest: The authors declare no conflict of interest.

\section{References}

1. Arrouays, D.; Lagacherie, P.; Hartemink, A. Digital soil mapping across the globe. Geoderma Reg. 2017, 9, 1-4. [CrossRef]

2. Ludwig, M.; Wilmes, P.; Schrader, S. Measuring soil sustainability via soil resilience. Sci. Total Environ. 2018, 626, 1484-1493. [CrossRef] [PubMed]

3. Shrivastava, P.; Kumar, R. Soil salinity: A serious environmental issue and plant growth promoting bacteria as one of the tools for its alleviation. Saudi J. Biol. Sci. 2015, 22, 123-131. [CrossRef] [PubMed]

4. Gorji, T.; Sertel, E.; Tanik, A. Monitoring soil salinity via remote sensing technology under data scarce conditions: A case study from Turkey. Ecol. Indic. 2017, 74, 384-391. [CrossRef]

5. Stolte, J.; Tesfai, M.; Oygarden, L.; Kvaerno, S.; Keizer, J.; Verheijen, F.; Panagos, P.; Ballabio, C.; Hessel, R. Soil Threats in Europe: Status, Methods, Drivers and Effects on Ecosystem Services: Deliverable 2.1 RECARE Project; European Commission DG Joint Research Centre: Strasbourg, France, 2016.

6. Wang, J.; Ding, J.; Yu, D.; Ma, X.; Zhang, Z.; Ge, X.; Teng, D.; Li, X.; Liang, J.; Lizaga, I.; et al. Capability of Sentinel-2 MSI data for monitoring and mapping of soil salinity in dry and wet seasons in the Ebinur Lake re-gion, Xinjiang, China. Geoderma 2019, 353, 172-187. [CrossRef]

7. Wang, F.; Shi, Z.; Biswas, A.; Yang, S.; Ding, J. Multi-algorithm comparison for predicting soil salinity. Geoderma 2020, $365,114211$. [CrossRef]

8. Ismayilov, A.I.; Mamedov, A.I.; Fujimaki, H.; Tsunekawa, A.; Levy, G.J. Soil Salinity Type Effects on the Rela-tionship between the Electrical Conductivity and Salt Content for 1: 5 Soil-to-Water Extract. Sustainability 2021, 13, 3395. [CrossRef]

9. Ivushkin, K.; Bartholomeus, H.; Bregt, A.K.; Pulatov, A.; Kempen, B.; de Sousa, L. Global mapping of soil salinity change. Remote Sens. Environ. 2019, 231, 111260. [CrossRef]

10. Seifi, M.; Ahmadi, A.; Neyshabouri, M.R.; Taghizadeh-Mehrjardi, R.; Bahrami, H.A. Remote and Vis-NIR pectra sensing potential for soil salinization estimation in the eastern coast of Urmia hyper saline lake, Iran. Remote Sensing Appl. Soc. Environ. 2020, 20, 100398.

11. Jiang, H.; Shu, H. Optical remote-sensing data based research on detecting soil salinity at different depth in an arid-area oasis, Xinjiang, China. Earth Sci. Inform. 2018, 12, 43-56. [CrossRef]

12. Wang, J.; Ding, J.; Yu, D.; Teng, D.; He, B.; Chen, X.; Ge, X.; Zhang, Z.; Wang, Y.; Yang, X.; et al. Ma-chine learning-based detection of soil salinity in an arid desert region, Northwest China: A comparison between Landsat-8 OLI and Sentinel-2 MSI. Sci. Total Environ. 2020, 707, 136092. [CrossRef] [PubMed]

13. Planet Imagery and Archive Home Page. Available online: https:/ /www.planet.com/products/planet-imagery/ (accessed on 9 January 2021).

14. Alpu 2012. Available online: http:/ / bebka.org.tr/admin/datas/sayfas/198/alpu-ilce-raporu_1568787633.pdf (accessed on 9 January 2021).

15. Bannari, A.; Guedon, A.M.; El-Harti, A.; Cherkaoui, F.Z.; El-Ghmari, A. Characterization of slightly and mod-erately saline and sodic soils in irrigated agricultural land using simulated data of advanced land imaging (EO-1) sensor. Commun. Soil Sci. Plant Anal. 2008, 39, 2795-2811. [CrossRef]

16. Abbas, A.; Khan, S. Using remote sensing techniques for appraisal of irrigated soil salinity. Int. Congr. Model. Simul. (MODSIM) Model. Simul. Soc. Aust. 2007, 2632-2638. 